\title{
Bilingualism as a Contributor to Cognitive Reserve? Evidence from Cerebral Glucose Metabolism in Mild Cognitive Impairment and Alzheimer's Disease
}

\author{
Magdalena Eva Kowoll ${ }^{*}$, Christina Degen ${ }^{1}$, Lina Gorenc ${ }^{1}$, Anika Küntzelmann ${ }^{2}$, \\ Iven Fellhauer ${ }^{1}$, Frederik Giesel ${ }^{3}$, Uwe Haberkorn ${ }^{3}$ and Johannes Schröder ${ }^{1}$ \\ 1 Section for Geriatric Psychiatry, University Clinic Heidelberg, Heidelberg, Germany, ${ }^{2}$ Department of Psychiatry and \\ Psychotherapy, University Hospital Leipzig, Leipzig, Germany, ${ }^{3}$ Department of Nuclear Medicine, University Clinic, \\ Heidelberg, Germany
}

OPEN ACCESS

Edited by:

Stefan Borgwardt, University of Basel, Switzerland

Reviewed by: Ellen Bialystok, York University, Canada Thomas Leyhe, Universitäre Psychiatrische Kliniken Basel, Switzerland

*Correspondence:

Magdalena Eva Kowoll magdalena-eva.kowolımed. uni-heidelberg.de

Specialty section: This article was submitted to Neuroimaging and Stimulation,

a section of the journal

Frontiers in Psychiatry

Received: 28 January 2016 Accepted: 29 March 2016

Published: 15 April 2016

Citation:

Kowoll ME, Degen C, Gorenc L, Küntzelmann A, Fellhauer I, Giesel F, Haberkorn U and Schröder J (2016)

Bilingualism as a Contributor to Cognitive Reserve? Evidence from

Cerebral Glucose Metabolism

in Mild Cognitive Impairment and Alzheimer's Disease.

Front. Psychiatry 7:62.

doi: 10.3389/fpsyt.2016.00062
Objective: Bilingualism is discussed as one factor contributing to "cognitive reserve" (CR), as it enhances executive control functions. To elucidate the underlying cerebral correlates, regional glucose uptake was compared between bilinguals and monolinguals with mild cognitive impairment (MCl) and beginning-stage Alzheimer's disease (AD) by using $\left[{ }^{18} \mathrm{~F}\right]$ fluorodeoxyglucose (FDG) positron emission tomography (PET).

Methods: Thirty patients $(73.2 \pm 7.4)$ diagnosed with $\mathrm{MCl}$ or probable $\mathrm{AD}$ received physical and neuropsychological examinations, blood tests, and FDG-PET scans. Sixteen patients were classified as lifelong bilinguals, following the criterion of Bialystok et al., and groups were matched for age, sex, and mini mental state examination scores. Analyses were conducted using statistical parametric mapping version 8. The whole brain was used as reference region for intensity normalization and years of education were controlled for.

Results: Bilingual patient groups showed substantially greater impairment of glucose uptake in frontotemporal and parietal regions [including Brodmann areas (BAs) 9, 47, 40, and 21] and in the left cerebellum relative to monolingual patients.

Conclusion: Bilingualism is likely to contribute to $\mathrm{CR}$, given that bilingual patients showed more severe brain changes than monolinguals when adjusting for severity of cognitive impairment. The latter did not only comprise BAs relevant to speech and language but also structures typically involved in AD pathology, such as the temporal and the parietal cortices.

Keywords: bilingualism, cognitive reserve, Alzheimer's disease, mild cognitive impairment, FDG-PET

\section{INTRODUCTION}

Lifelong bilingualism is associated with higher cognitive reserve (CR), as it is linked to relatively delayed onset of Alzheimer's disease (AD)-related cognitive deficits (1-4) and the manifestation of mild cognitive impairment (MCI) and AD (4-6). CR facilitates compensation of pathological cerebral changes for a longer period of time; hence, in neuroimaging studies, patients with higher 
CR typically show more pronounced changes than those with a low CR despite similar levels of impairment. The only study to test this effect in bilinguals was presented by Schweizer et al. (7), who compared indices of brain atrophy using computed tomography (CT) scans of 20 monolingual and 20 bilingual patients diagnosed with probable $\mathrm{AD}$, carefully matched for level of cognitive performance and years of education. Bilingual patients with $\mathrm{AD}$ exhibited substantially more pronounced brain atrophy than monolingual patients in indices sensitive to mid temporal changes, specifically the radial width of the temporal horn and the temporal horn ratio.

In the present study, we sought to investigate differences in cerebral glucose metabolism between bilinguals and monolinguals with MCI and AD using $\left[{ }^{18} \mathrm{~F}\right]$ fluorodeoxyglucose (FDG) positron emission tomography (PET) under a resting condition, i.e., a neuroimaging technique particularly sensitive to detect $\mathrm{AD}$-related brain changes. We expected to find a substantially greater impairment of glucose uptake in bilinguals than monolinguals.

\section{MATERIALS AND METHODS}

\section{Participants}

A total of 30 subjects were recruited between June 2012 and March 2014 from the Memory Clinic of the University of Heidelberg. Fourteen subjects were classified as monolinguals, 16 as lifelong bilinguals, following Bialystok et al.s [p. 460, Ref. (1)] criterion: patients were classified as bilingual if they “... had spent the majority of their lives, at least from early adulthood, regularly using at least two languages," 12 were diagnosed with MCI, according to the aging-associated cognitive decline criteria [AACD; (8)], and 18 individuals were diagnosed with AD, using the NINCDS-ADRDA criteria (9). Diagnoses were established by consensus between an experienced geriatric psychiatrist and an experienced psychologist.

The bilingual participants consisted of speakers of nine different first languages, of which the most common were German $(N=7)$ and Hungarian $(N=2)$. There were seven different second languages spoken, the most common were German $(N=8)$ and English $(N=3)$. Also, $68.8 \%(N=11)$ of bilinguals were multilinguals and were able to use more than two languages. Twelve bilinguals were immigrants to Germany. Their countries of origin were Hungary $(N=2)$, Czechoslovakia, Finland, Palestine, Poland, Peru, Serbia, Slovakia, Taiwan, Trinidad, and Turkey (each $N=1$ ).

\section{Procedure}

The study was approved by the Ethical Committee of the University of Heidelberg. After complete description of the study to the participants, informed consent was obtained. Participants were carefully screened for language history, occupational history, fluency in German and other languages, place of birth, and date of immigration.

\section{Neuropsychological Test Battery}

Neuropsychological assessment contained the German version of the CERAD-NP neuropsychological assessment battery $(10,11)$, the mini-mental state examination (MMSE), the Trail Making
Test (TMT) (12), the subtests logical memory and digit span of the German version of Wechsler Memory Scale (WMS-R and WMS-IV) $(13,14)$, and the clock-drawing test (15). Furthermore, the short version of the Geriatric Depression Scale (GDS) (16) was obtained to exclude depressive symptoms. On the basis of interviews and tests, severity of dementia was rated by using the Global Deterioration Scale (17).

\section{PET Acquisition Protocol}

Following a 6-h fasting, blood glucose level was determined and shown to be below $110 \mathrm{mg} / \mathrm{dl}$ in all subjects, before the injection of 118-196 MBq FDG. From 15 min before until 45 min after injection, participants rested in a quiet room with dimmed light. They were instructed to keep their eyes closed. Afterward, 20-min PET scans were acquired. Measurements were obtained with a Biograph 6 by Siemens (thickness of each slice: $5 \mathrm{~mm}, \mathrm{kVp}$ : 130, pixel size: $0.59 \mathrm{~mm} \times 0.59 \mathrm{~mm}$, and matrix: $512 \times 512$ ) [for details, see Ref. $(18,19)]$.

\section{Image Analysis}

Statistical parametric mapping version 8 (SPM8) routines with default settings were used for basic image processing. ${ }^{1}$ Global normalization was conducted using the proportional scaling option as provided by SPM8. Images were spatially normalized to the Montreal Neurological Institute PET template, written on a matrix with $2 \mathrm{~mm} \times 2 \mathrm{~mm} \times 2 \mathrm{~mm}$ voxel size, and smoothed by an isotropic Gaussian filter of $12 \mathrm{~mm}$ full width at half maximum [for details, see Ref. (19)].

\section{Statistical Analyses}

For statistical analyses, raw data from the individual CERAD, WMS, and TMT subscores were transformed into $z$-scores that were adjusted for age, gender, and years of education (11-14).

For voxel-based parametric analysis with SPM8, years of education were entered as a covariate. The predicted value was the global normalized glucose uptake. Assuming independency and normal distribution of error terms and homoscedasticity, we performed pairwise one-sided $t$-contrasts for the effect of language group using the contrast matrix $(-1,1)$ (bilingual $<$ monolingual). Significance level was set to $p<0.05$ (uncorrected) with cluster extent threshold $k>30$. The respective structures were identified by their coordinates, according to the Talairach atlas (20) using the Talairach client applet version 2.4.2. ${ }^{2}$ SPSS for Windows version 22 was used for statistical analyses; $p<0.05$ was considered significant. Likelihood-ratio tests were used where appropriate [for details, see Ref. (19)].

\section{RESULTS}

Demographic and clinical characteristics of the language groups and the total sample are provided in Table $\mathbf{1 .}$

Bilinguals have had more years of education than monolinguals. Moreover, bilinguals were more likely to be immigrants

${ }^{1}$ http://www.fil.ion.ucl.ac.uk/spm/software/spm8/

${ }^{2}$ http://www.talairach.org/index.html 
TABLE 1 | Demographic and clinical characteristics of bilingual and monolingual patients with $\mathrm{MCl}$ and AD.

\begin{tabular}{|c|c|c|c|c|c|}
\hline $\mathrm{M} \pm \mathrm{SD} / \mathrm{N}$ & Total sample & $\begin{array}{l}\text { Bilinguals with } \mathrm{MCl} \text { and } \mathrm{AD} \\
\text { (A) }\end{array}$ & $\begin{array}{l}\text { Monolinguals with } \mathrm{MCl} \text { and } \mathrm{AD} \\
\text { (B) }\end{array}$ & $t$-Test/likelihood ratio & \\
\hline$N$ & 30 & 16 & 14 & & \\
\hline Age & $73.2(7.4)$ & $74.6(6.8)$ & $71.6(7.9)$ & $\begin{aligned} t(28) & =1.109 \\
p & =0.277\end{aligned}$ & \\
\hline$\delta / q$ & $14 / 16$ & $8 / 8$ & $6 / 8$ & $\begin{aligned} \operatorname{LR}(1) & =0.153 \\
p & =0.695\end{aligned}$ & \\
\hline MMSE & $24.4(2.9)$ & $24.9(2.7)$ & $23.9(3.1)$ & $\begin{aligned} t(28) & =0.955 \\
p & =0.348\end{aligned}$ & \\
\hline Years of education & $13.6(4.0)$ & $15.3(3.6)$ & $11.7(3.7)$ & $\begin{aligned} t(28) & =2.644^{*} \\
p & =0.013\end{aligned}$ & $A>B$ \\
\hline $\mathrm{MCl} / \mathrm{AD}$ & $12 / 18$ & $5 / 11$ & $7 / 7$ & $\begin{aligned} \operatorname{LR}(3) & =41.455^{\star \star \star} \\
p & =0.000\end{aligned}$ & \\
\hline Geriatric Depression Scale & 2.7 (3.3) & $2.7(3.1)$ & $2.6(3.7)$ & $\begin{aligned} t(26) & =0.091 \\
p & =0.928\end{aligned}$ & \\
\hline
\end{tabular}

$L R$, likelihood quotient.

${ }^{*} p<0.05$.

${ }^{* * *} p \leq 0.001$.

than monolinguals and exhibited a higher proportion of $\mathrm{AD}$ pathology as opposed to MCI. Scores on the GDS, the Global Deterioration Scale, and the MMSE showed only minor, nonsignificant differences between groups (Table 1).

Neuropsychological performance was compared between language groups (Table 2). Overall performance was affected equally in monolinguals and bilinguals. No significant differences occurred.

Significant differences in FDG uptake were restricted to lower values in the bilingual vs. monolingual comparison and involved both right and left frontal, temporal and parietal cortices, and the left cerebellum (Figure 1).

As given in Table 3, these regions included Brodmann area (BA) $9,21,40$, and 47.

\section{DISCUSSION}

The present study yielded significantly lower glucose uptake in bilingual compared to monolingual patients with MCI or early $\mathrm{AD}$, although both groups were comparable on clinical grounds. Differences in glucose uptake were localized in areas important for speech and language, mainly involving the frontal cortices as well as in temporoparietal areas traditionally associated with AD pathology (21) and in the left cerebellum. These regions included BA 9 (right), 21 (right), 40 (right and left), and 47 (left). There were no significant differences in neuropsychological domains between monolinguals and bilinguals. These results are in line with the results of Kowoll et al. (22), who showed that bilingual $\mathrm{MCI}$ and AD patients showed a similar pattern of neuropsychological deficits as monolingual patients did. This finding also included the TMT-B, which addresses aspects of frontal executive functioning - a domain which seems to be enhanced in healthy bilinguals [(23-25); reviewed in Ref. (26)]. The performance in the BNT - a test in which healthy monolingual subjects usually achieve better scores [(24, 27); reviewed in Ref. (28)] was equally affected in the two language groups in this analysis. Since groups showed only minor, non-significant differences with respect to severity of cognitive deficits, these findings corroborate the hypothesis that bilingualism facilitates compensation of cerebral changes and can thus contribute to CR. That bilinguals also show differences in centers responsible for speech and language processing seems plausible, given the fact that patients differed with respect to language (monolinguals vs. bilinguals) while displaying similar degrees of cognitive impairment.

Brodmann area 9 in the right hemisphere is located in the frontal cortex and contributes to dorsolateral and medial prefrontal cortex functions linked to working memory (29), visuospatial memory (30), and planning (31). BA 21 is located in the middle temporal gyrus, which is involved in language and semantic memory processing (32-35). Likewise, Schröder et al. (21) found BA 21 (both right and left) to be involved in a declarative memory task, using FDG-PET. BA 40 includes Wernicke's area of the supramarginal gyrus and is functionally involved in reading, meaning, and phonology (36). BA 47 has been implicated in the processing of fine structured stimuli that evolve over time, not merely those that are linguistic (37). Moreover, Dos Santos et al. (38) analyzed neuropsychological deficits with respect to morphometric changes in 94 patients with $\mathrm{MCI}$ and $\mathrm{AD}$ and found deficits in verbal fluency and word recognition to be significantly correlated with changes in the left gyrus frontalis inferior (BA 47).

Our findings parallel the results reported by Gold et al. (39), who provided the first direct evidence of a neural basis for 
TABLE 2 | z-Scores (means) for the subscales "logical memory" and "digit span" of the Wechsler Memory Scale and TMT and the subscales of CERAD-NP in bilinguals and monolinguals with $\mathrm{MCl}$ and AD.

\begin{tabular}{|c|c|c|c|c|}
\hline$M \pm S D / N$ & Total sample & $\begin{array}{c}\text { Bilinguals with } \mathrm{MCl} \text { and } \mathrm{AD} \\
\text { (A) }\end{array}$ & $\begin{array}{l}\text { Monolinguals with } \mathrm{MCl} \text { and AD } \\
\text { (B) }\end{array}$ & $t$-Test \\
\hline$N$ & 30 & 16 & 14 & \\
\hline Word list immediate recall & $-2.2(1.2)$ & $-2.0(1.4)$ & $-2.3(0.8)$ & $\begin{aligned} t(25) & =0.595 \\
p & =0.557\end{aligned}$ \\
\hline Word list delayed recall & $-1.8(1.2)$ & $-1.5(1.3)$ & $-2.2(1.0)$ & $\begin{aligned} t(25) & =1.534 \\
p & =0.138\end{aligned}$ \\
\hline Word list recognition & $-1.5(2.3)$ & $-1.5(2.7)$ & $-1.5(1.6)$ & $\begin{aligned} t(25) & =-0.059 \\
p & =0.954\end{aligned}$ \\
\hline Constructional praxis & $-0.3(1.6)$ & $-0.1(1.3)$ & $-0.6(2.0)$ & $\begin{aligned} t(27) & =0.848 \\
p & =0.404\end{aligned}$ \\
\hline Constructional praxis recall & $-2.1(1.7)$ & $-2.1(1.9)$ & $-2.0(1.3)$ & $\begin{aligned} t(27) & =-0.139 \\
p & =0.890\end{aligned}$ \\
\hline Verbal fluency & $-1.3(1.0)$ & $-1.4(0.8)$ & $-1.2(1.3)$ & $\begin{aligned} t(28) & =-0.515 \\
p & =0.611\end{aligned}$ \\
\hline BNT & $-0.8(1.7)$ & $-0.4(1.4)$ & $-1.2(1.9)$ & $\begin{aligned} t(28) & =1.446 \\
p & =0.159\end{aligned}$ \\
\hline TMT-A & $-3.3(4.6)$ & $-3.7(5.4)$ & $-2.7(3.7)$ & $\begin{aligned} t(28) & =-0.560 \\
p & =0.580\end{aligned}$ \\
\hline TMT-B & $-4.2(6.4)$ & $-4.0(7.4)$ & $-4.5(5.3)$ & $\begin{aligned} t(20) & =0.190 \\
p & =0.851\end{aligned}$ \\
\hline Logical memory I & $-2.1(1.1)$ & $-2.0(1.2)$ & $-2.1(1.1)$ & $\begin{aligned} t(26) & =0.279 \\
p & =0.782\end{aligned}$ \\
\hline Logical memory II & $-2.5(1.0)$ & $-2.3(1.0)$ & $-2.7(0.9)$ & $\begin{aligned} t(26) & =1.015 \\
p & =0.320\end{aligned}$ \\
\hline Digit span forward & $-1.0(1.0)$ & $-1.0(1.2)$ & $-1.1(0.8)$ & $\begin{aligned} t(28) & =0.255 \\
p & =0.801\end{aligned}$ \\
\hline Digit span backward & $-0.9(1.0)$ & $-0.9(0.9)$ & $-0.9(1.0)$ & $\begin{aligned} t(28) & =-0.111 \\
p & =0.912\end{aligned}$ \\
\hline
\end{tabular}

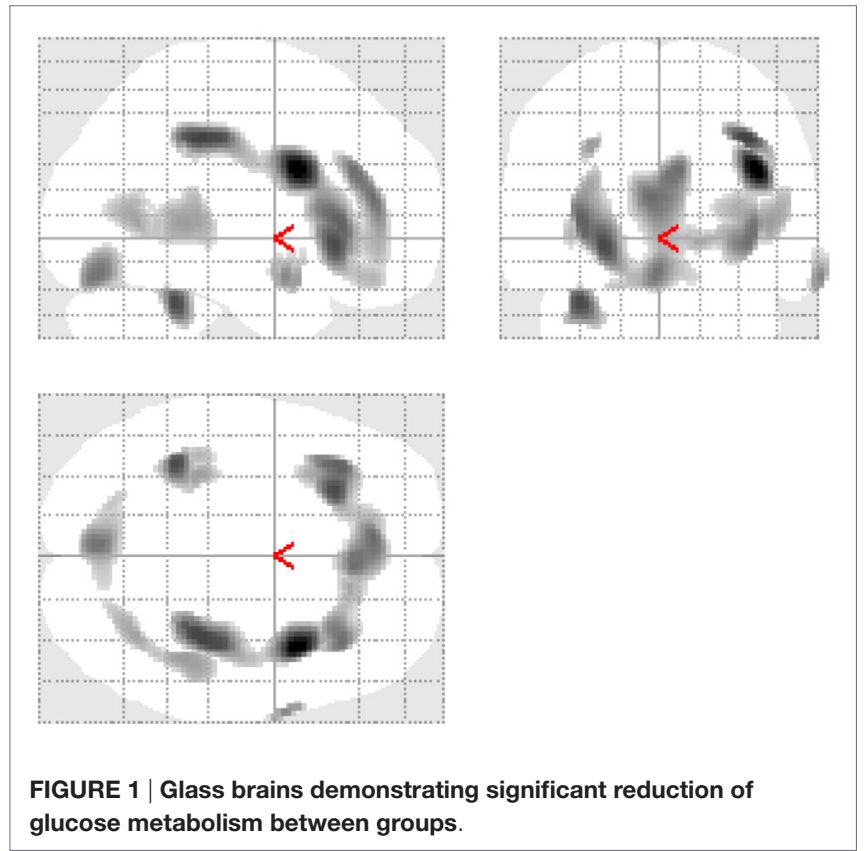

bilingual cognitive control advantages in aging. The authors compared the reaction times of 80 younger and older adult monolinguals and bilinguals who completed the same perceptual
TABLE 3 | Reduced glucose metabolism in bilingual $M C l$ and $A D$ patients vs. monolingual $\mathrm{MCl}$ and $A D$ patients.

\begin{tabular}{|c|c|c|c|c|c|c|c|c|}
\hline & Location & BA & $\begin{array}{l}\text { Cluster } \\
\text { extension }\end{array}$ & $\begin{array}{c}\text { Peak } \\
\text { z-value }\end{array}$ & $p$ & $x$ & $y$ & $z$ \\
\hline $\mathbf{R}$ & $\begin{array}{l}\text { Gyrus frontalis } \\
\text { inferior }\end{array}$ & 9 & 3357 & 2.56 & 0.005 & 40 & 8 & 26 \\
\hline $\mathrm{R}$ & Inferior parietal lobe & 40 & & 2.28 & 0.011 & 36 & -32 & 38 \\
\hline $\mathrm{L}$ & Gyrus frontalis inferior & 47 & & 2.25 & 0.012 & -26 & 24 & -6 \\
\hline $\mathbf{L}$ & $\begin{array}{l}\text { Cerebellum, } \\
\text { culmen }\end{array}$ & - & 207 & 2.25 & 0.012 & -36 & -44 & -30 \\
\hline $\mathbf{L}$ & Cerebellum & - & 441 & 2.08 & 0.019 & -4 & -78 & -18 \\
\hline $\mathrm{L}$ & Cerebellum, declive & - & & 1.76 & 0.039 & -20 & -72 & -22 \\
\hline $\mathbf{R}$ & $\begin{array}{l}\text { Gyrus temporalis } \\
\text { medius }\end{array}$ & 21 & 51 & 2.00 & 0.023 & 66 & 2 & -18 \\
\hline \multirow[t]{4}{*}{$\mathbf{L}$} & Inferior parietal & 40 & 40 & 1.93 & 0.027 & -32 & -34 & 34 \\
\hline & & - & 472 & 1.92 & 0.027 & 44 & -40 & 4 \\
\hline & & - & & 1.90 & 0.029 & 34 & -60 & 4 \\
\hline & & - & & 1.78 & 0.037 & 42 & -52 & 2 \\
\hline $\mathbf{L}$ & $\begin{array}{l}\text { Temporal lobe, } \\
\text { sub-gyral }\end{array}$ & - & 89 & 1.83 & 0.034 & -40 & -34 & 0 \\
\hline
\end{tabular}

$R$, right; L, left; $B A$, Brodmann area.

Cluster extension represents the number of contiguous voxel passing the threshold of $p<0.05$. Bold markings delineate a cluster and the peak $z$-value. Brain regions are indicated by Talairach and Tournoux coordinates, $x, y$, and $z$ : $x$ : the medial to lateral distance relative to the midline (positive: right hemisphere), $y$ : the anterior to posterior distance relative to the anterior commissure (positive: anterior), and z: the superior to inferior distance relative to the anterior commissure-posterior commissure line (positive: superior) [for details, see Ref. (18)]. 
task-switching experiment while functional magnetic resonance imaging (fMRI) was conducted. The researchers observed that bilingual older adults outperformed their monolingual peers with decreased signaling in left lateral frontal and cingulate cortices. This activation increases were directly correlated with enhanced performance on the task-switching task.

Corroborating results of Schweizer et al. (7), our FDG-PET study shows that a group of bilingual patients with $\mathrm{AD}$ exhibit substantially greater amounts of brain pathology than monolingual patients when the two groups were matched for level of severity of impairment. Differences in years of education between the two groups were statistically controlled for.

The respective brain regions identified in our study are not only associated with speech and language but also implicated in a number of cognitive functions typically compromised in $\mathrm{AD}$.

\section{REFERENCES}

1. Bialystok E, Craik FIM, Freedman M. Bilingualism as a protection against the onset of symptoms of dementia. Neuropsychologia (2007) 45:459-64. doi:10.1016/j.neuropsychologia.2006.10.009

2. Craik FIM, Bialystok E, Freedman M. Delaying the onset of Alzheimer disease: bilingualism as a form of cognitive reserve. Neurology (2010) 75:1726-9. doi:10.1212/WNL.0b013e3181fc2a1c

3. Alladi S, Bak TH, Duggirala V, Surampudi B, Shailaja M, Shukla AK, et al. Bilingualism delays age at onset of dementia, independent of education and immigration status. Neurology (2013) 81:1938-44. doi:10.1212/01. wnl.0000436620.33155.a4

4. Bialystok E, Craik FI, Binns MA, Ossher L, Freedman M. Effects of bilingualism on the age of onset and progression of $\mathrm{MCI}$ and $\mathrm{AD}$ : evidence from executive function tests. Neuropsychology (2014) 28:290-304. doi:10.1037/neu0000023

5. Gollan TH, Salmon DP, Montoya RI, Galasko DR. Degree of bilingualism predicts age of diagnosis of Alzheimer's disease in low-education but not in highly educated Hispanics. Neuropsychologia (2011) 49:3826-30. doi:10.1016/j. neuropsychologia.2011.09.041

6. Ossher L, Bialystok E, Craik FIM, Murphy KJ, Troyer AK. The effect of bilingualism on amnestic mild cognitive impairment. J Gerontol B Psychol Sci Soc Sci (2013) 68:8-12. doi:10.1093/geronb/gbs038

7. Schweizer TA, Ware J, Fischer CE, Craik FIM, Bialystok E. Bilingualism as a contributor to cognitive reserve: evidence from brain atrophy in Alzheimer's disease. Cortex (2012) 48:991-6. doi:10.1016/j.cortex.2011.04.009

8. Levy R. Aging-associated cognitive decline. Working Party of the International Psychogeriatric Association in collaboration with the World Health Organization. Int Psychogeriatr (1994) 6:63-8. doi:10.1017/ S1041610294001626

9. McKhann G, Drachman D, Folstein M, Katzman R, Price D, Stadlan EM. Clinical diagnosis of Alzheimer's disease: report of the NINCDS-ADRDA Work Group under the auspices of Department of Health and Human Services Task Force on Alzheimer's disease. Neurology (1984) 34:939-44. doi:10.1212/ WNL.34.7.939

10. Morris JC, Heyman A, Mohs RC, Hughes JP, van Belle G, Fillenbaum G, et al. The Consortium to Establish a Registry for Alzheimer's Disease (CERAD). Part I. Clinical and neuropsychological assessment of Alzheimer's disease. Neurology (1989) 39:1159-65. doi:10.1212/WNL.39.9.1159

11. Barth S, Schonknecht P, Pantel J, Schroder J. Mild cognitive impairment and Alzheimer's disease: an investigation of the CERAD-NP test battery. Fortschr Neurol Psychiatr (2005) 73:568-76. doi:10.1055/s-2004-830249

12. Tombaugh TN. Trail making test A and B: normative data stratified by age and education. Arch Clin Neuropsychol (2004) 19:203-14. doi:10.1016/ S0887-6177(03)00039-8

13. Härting C, Markowitsch H-J, Neufeld H, Calabrese P, Deisinger K, Kessler J. Wechsler Memory Scale - Revised Edition, German Edition. Bern: Huber (2000).
These findings indicate that bilinguals can compensate for more severe cerebral changes than monolingual patients in the early phases of AD.

\section{AUTHOR CONTRIBUTIONS}

All authors listed have made substantial, direct, and intellectual contribution to the work, and approved it for publication.

\section{FUNDING}

The study was supported by the "Ministry for Work, Social Order, Family, Women and Senior Citizen" of the State BadenWürttemberg, Germany, and the "Robert Bosch Foundation/ Stuttgart," Germany.

14. Petermann F, Lepach AC, editors. Wechsler Memory Scale - Fourth Edition Deutsche Übersetzung und Adaption des WMS-IV von David Wechsler. Frankfurt: Pearson (2012).

15. Shulman KI, Gold DP, Cohen CA, Zucchero CA. Clock-drawing and dementia in the community: a longitudinal study. Int J Geriatr Psychiatry (1993) 8:487-96. doi:10.1002/gps.930080606

16. Sheikh JI, Yesavage JA. Geriatric Depression Scale (GDS): recent evidence and development of a shorter version. Clin Gerontol (1986) 5:165-73. doi:10.1300/ J018v05n01_09

17. Reisberg B, Ferris SH, de Leon MJ, Crook T. The Global Deterioration Scale for assessment of primary degenerative dementia. Am J Psychiatry (1982) 139:1136-9. doi:10.1176/ajp.139.9.1136

18. Hunt A, Schonknecht P, Henze M, Seidl U, Haberkorn U, Schroder J. Reduced cerebral glucose metabolism in patients at risk for Alzheimer's disease. Psychiatry Res (2007) 155:147-54. doi:10.1016/j.pscychresns.2006.12.003

19. Küntzelmann A, Guenther T, Haberkorn U, Essig M, Giesel F, Henze R, et al. Impaired cerebral glucose metabolism in prodromal Alzheimer's disease differs by regional intensity normalization. Neurosci Lett (2013) 534:12-7. doi:10.1016/j.neulet.2012.11.026

20. Talairach J, Tournoux P. Co-Planar Stereotaxic Atlas of the Human Brain: 3-Dimensional Proportional System; An Approach to Cerebral Imaging. Stuttgart: Thieme (1988).

21. Schröder J, Buchsbaum MS, Shihabuddin L, Tang C, Wei TC, SpiegelCohen J, et al. Patterns of cortical activity and memory performance in Alzheimer's disease. Biol Psychiatry (2001) 49:426-36. doi:10.1016/ S0006-3223(00)00983-5

22. Kowoll ME, Degen C, Gladis S, Schroder J. Neuropsychological profiles and verbal abilities in lifelong bilinguals with mild cognitive impairment and Alzheimer's disease. J Alzheimers Dis (2015) 45:1257-68. doi:10.3233/ JAD-142880

23. Bialystok E, Craik FI, Klein R, Viswanathan M. Bilingualism, aging, and cognitive control: evidence from the Simon task. Psychol Aging (2004) 19:290-303. doi:10.1037/0882-7974.19.2.290

24. Bialystok E, Craik F, Luk G. Cognitive control and lexical access in younger and older bilinguals. JExp Psychol Learn Mem Cogn (2008) 34:859-73. doi:10.1037/0278-7393.34.4.859

25. Christoffels IK, Haan AM, Steenbergen L, Wildenberg WPM, Colzato LS. Two is better than one: bilingual education promotes the flexible mind. Psychol Res (2015) 79:371-9. doi: 10.1007/s00426-014-0575-3

26. Costa A, Sebastian-Galles N. How does the bilingual experience sculpt the brain? Nat Rev Neurosci (2014) 15:336-45. doi:10.1038/nrn3709

27. Roberts PM, Garcia LJ, Desrochers A, Hernandez D. English performance of proficient bilingual adults on the Boston naming test. Aphasiology (2002) 16:635-45. doi:10.1080/02687030244000220

28. Hilchey MD, Klein RM. Are there bilingual advantages on nonlinguistic interference tasks? Implications for the plasticity of executive control processes. Psychon Bull Rev (2011) 18:625-58. doi:10.3758/s13423-011-0116-7 
29. Zhang JX, Leung H-C, Johnson MK. Frontal activations associated with accessing and evaluating information in working memory: an fMRI study. Neuroimage (2003) 20:1531-9. doi:10.1016/j.neuroimage.2003.07.016

30. Slotnick SD, Moo LR. Prefrontal cortex hemispheric specialization for categorical and coordinate visual spatial memory. Neuropsychologia (2006) 44:1560-8. doi:10.1016/j.neuropsychologia.2006.01.018

31. Fincham JM, Carter CS, van Veen V, Stenger VA, Anderson JR. Neural mechanisms of planning: a computational analysis using event-related fMRI. Proc Natl Acad Sci U S A (2002) 99:3346-51. doi:10.1073/pnas.052703399

32. Tranel D, Damasio H, Damasio AR. A neural basis for the retrieval of conceptual knowledge. Neuropsychologia (1997) 35:1319-27. doi:10.1016/ S0028-3932(97)00085-7

33. Chao LL, Haxby JV, Martin A. Attribute-based neural substrates in temporal cortex for perceiving and knowing about objects. Nat Neurosci (1999) 2:913-9. doi:10.1038/13217

34. Cabeza R, Nyberg L. Imaging cognition II: an empirical review of 275 PET and fMRIstudies.J CognNeurosci(2000) 12:1-47.doi:10.1162/08989290051137585

35. Onitsuka T, Shenton ME, Salisbury DF, Dickey CC, Kasai K, Toner SK, et al. Middle and inferior temporal gyrus gray matter volume abnormalities in chronic schizophrenia: an MRI study. Am J Psychiatry (2004) 161:1603-11. doi:10.1176/appi.ajp.161.9.1603

36. Stoeckel C, Gough PM, Watkins KE, Devlin JT. Supramarginal gyrus involvement in visual word recognition. Cortex (2009) 45:1091-6. doi:10.1016/j. cortex.2008.12.004
37. Levitin DJ, Menon V. Musical structure is processed in "language" areas of the brain: a possible role for Brodmann area 47 in temporal coherence. Neuroimage (2003) 20:2142-52. doi:10.1016/j.neuroimage. 2003.08.016

38. Dos Santos V, Thomann PA, Wüstenberg T, Seidl U, Essig M, Schröder J. Morphological cerebral correlates of CERAD test performance in mild cognitive impairment and Alzheimer's disease. JAlzheimers Dis (2011) 23:411-20. doi:10.3233/JAD-2010-100156

39. Gold BT, Kim C, Johnson NF, Kryscio RJ, Smith CD. Lifelong bilingualism maintains neural efficiency for cognitive control in aging. J Neurosci (2013) 33:387-96. doi:10.1523/jneurosci.3837-12.2013

Conflict of Interest Statement: The authors declare that the research was conducted in the absence of any commercial or financial relationships that could be construed as a potential conflict of interest.

Copyright ( 2016 Kowoll, Degen, Gorenc, Küntzelmann, Fellhauer, Giesel, Haberkorn and Schröder. This is an open-access article distributed under the terms of the Creative Commons Attribution License (CC BY). The use, distribution or reproduction in other forums is permitted, provided the original author $(s)$ or licensor are credited and that the original publication in this journal is cited, in accordance with accepted academic practice. No use, distribution or reproduction is permitted which does not comply with these terms. 